\title{
Alumina ceramics by sol-gel technique
}

\author{
S RAMANATHAN, R BHAT, D D UPADHYAYA and S K ROY \\ Metallurgy Division, Bhabha Atomic Research Centre, Bombay 400085 , India \\ MS received 20 August 1993; revised 26 October 1993
}

\begin{abstract}
The processing of alumina ceramics using the sol-gel technique was investigated. Alumina sols were prepared by precipitation-peptization of aluminium hydroxide obtained from aluminium nitrate and aluminium oxyhydroxide obtained from aluminium isopropoxide. Sols cast on Teflon substrate were gelled by controlled dehydration at near-ambient temperature. Gels were converted to ceramics through processes of drying, calcination and sintering in the temperature range $773-1473 \mathrm{~K}$. Ceramics derived from both the sols retained a porosity of $35-45 \%$ even after sintering at $1273 \mathrm{~K}$. However, at $1473 \mathrm{~K}$ densification was drastically enhanced and bodies could be sintered to about $90-93 \%$ of theoretical density (TD) and was accompanied by the $\theta$-to- $\alpha$ transformation. The progress of the reactions occurring at various stages of the process was studied using pycnometry, TG-DSC, XRD, SEM, MIP and TEM techniques.
\end{abstract}

Keywords. Alumina; sol-gel.

\section{Introduction}

Advanced applications of alumina ceramics with controlled characteristics vary from high-porosity (fine and uniform pore size coupled with high specific surface area) bodies for catalyst carriers, microfilters and humidity sensors to high-density nanograin-sized monoliths. One of the recent processing methods for this is through sol-gel technique. By suitably varying the processing conditions-sol formation, gelation, expulsion of volatiles and sintering - it is possible to obtain alumina ceramics with designed features encompassing a wide spectrum of microstructure. The objective of the present work is to characterize individual steps involved in the sol-gel processing of alumina ceramics (monoliths) through a detailed study on the preparation of the sol, gelation, removal of volatiles, crystallization, sintering behaviour and microstructure evolution.

\section{Experimental}

An alumina sol was prepared by peptizing the aluminium hydroxide (obtained by precipitation from a $0.2 \mathrm{M}$ aluminium nitrate solution with ammonia) using acetic acid (up to a molar ratio of acetate to aluminium of $0.4, \mathrm{pH} \mathrm{4.4)}$ ) at a temperature of $363 \mathrm{~K}$ with vigorous stirring. This could be finally concentrated to $1 \mathrm{M}$ with respect to aluminium (sol-1). Another sol of the same concentration was prepared by peptizing with nitric acid (molar ratio of nitrate to aluminium $0.4, \mathrm{pH} 3.8$ ), the hydroxide precipitate obtained by hydrolysis of aluminium isopropoxide under similar conditions (sol-2). The sols were cast in Teflon dishes and allowed to undergo gelation by slow and controlled evaporation of water at room temperature in closed environment for $120 \mathrm{~h}$ so that defects like crack and nonuniform shrinkage could be minimized. The dried thick elastic gel films (monoliths) with entrapped volatiles were subjected to 
characterization by TG and DSC. The sintering of the gels was carried out under the heating schedule of $1 \mathrm{~K} \mathrm{~min}^{-1}$ up to $773 \mathrm{~K}$ and $6 \mathrm{~K} \mathrm{~min}^{-1}$ above $773 \mathrm{~K}$ till the desired temperature was reached and was followed by $\mathrm{a} 2 \mathrm{~h}$ soaking at that temperature. The samples were characterized for bulk density by liquid displacement (Burman balance), surface area by BET, pore size distribution by mercury intrusion porosimeter, phase evaluation by XRD, and microstructure by SEM and TEM.

\section{Results and discussion}

Table 1 shows the characteristics of the sol obtained under different conditions of peptization. It is obvious that an initial ratio of about 0.4 of acetate or nitrate to aluminium was essential to obtain a transparent sol of $1 \mathrm{M}$ concentration of aluminium for both hydroxides obtained from hydrolysis of aluminium nitrate and aluminium isopropoxide. The $\mathrm{pH}$ of precipitation, time, temperature and vigorous stirring were found to be the critical parameters in obtaining easy peptization. The course of gelation was followed by weight loss of the sol due to evaporation with time. For both the transparent sols a reduction in the rate of drying is exhibited as gelation sets (figure 1) and the monoliths obtained were crack-free. It is evident from this figure that the derived gel from sol- 2 has a lower volatile content than that from sol-1. The role of the counterions (nitrate and acetate) and $\mathrm{pH}$ on the stability of the

Table 1. Effect of acid to aluminium ratio on peptization.

\begin{tabular}{|c|c|c|c|}
\hline $\begin{array}{l}\text { Type of } \\
\text { sol }\end{array}$ & $\begin{array}{l}\text { Mole ratio of acid } \\
\text { to aluminium }\end{array}$ & pH & $\begin{array}{l}\text { Condition after annealing } \\
\text { at } 363 \mathrm{~K} \text { for } 5 \text { days }\end{array}$ \\
\hline & 0.04 & $5 \cdot 8$ & Not peptized \\
\hline \multirow[t]{2}{*}{ Sol-1 } & 0.20 & $4 \cdot 8$ & $\begin{array}{l}\text { Peptized but unclear upon } \\
\text { concentration to } 1 \mathrm{M}\end{array}$ \\
\hline & 0.40 & $4 \cdot 4$ & Clear sol at $1 \mathbf{M}$ \\
\hline Sol-2 & 0.40 & 3.8 & Clear sol at $1 \mathrm{M}$ \\
\hline
\end{tabular}

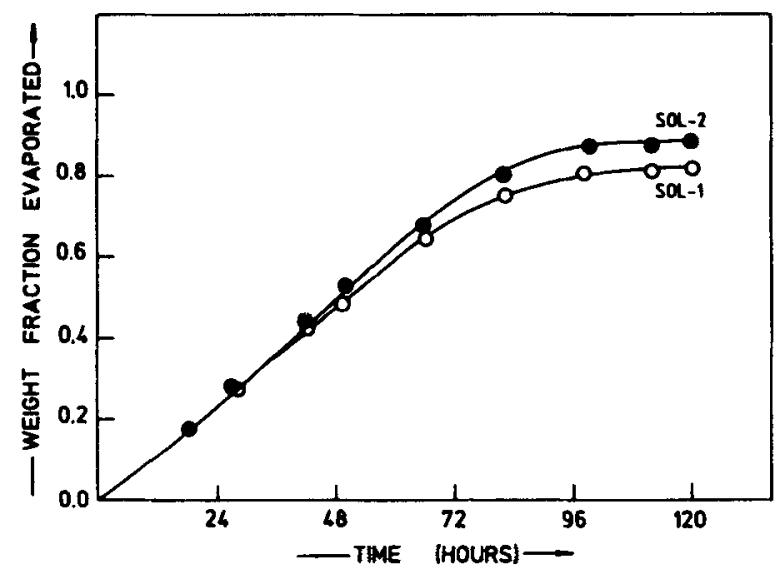

Figure 1. Variation of fraction evaporated with time of gelation. 


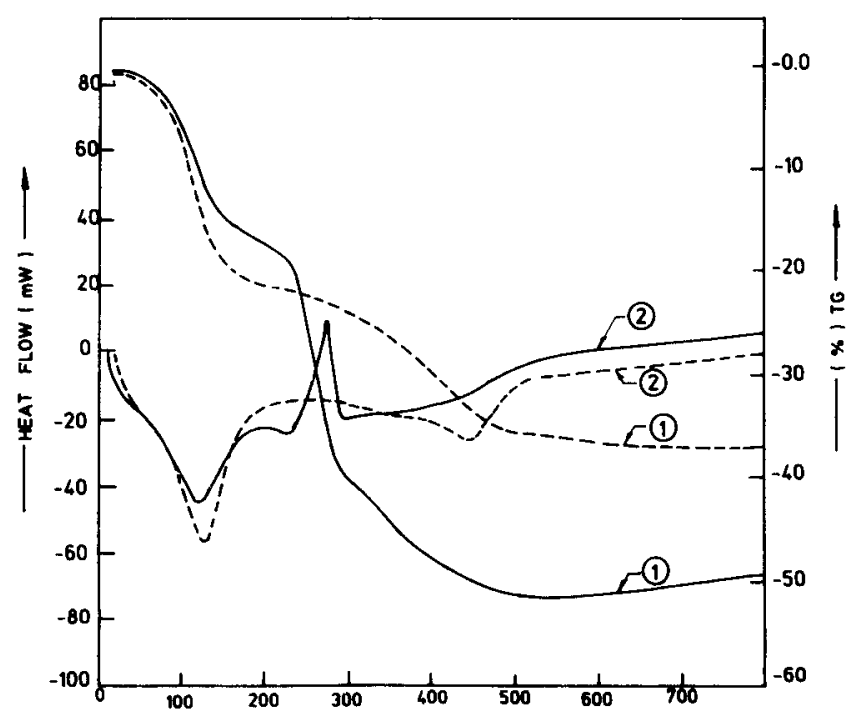

Figure 2. Typical DSC and TG traces for alumina gels $(-$, gel 1; -.--, gel 2; 1. TG and 2. DSC).

sols and gelation process without coagulation could be attributed to the appropriate charge distribution existing between the sol particle and medium throughout the course of sol-to-gel transformation (Matijevic 1973; Yoldas 1975a).

The devolatilization behaviour of these elastic polymer monoliths was studied using TG and DSC (figure 2). It is obvious that the first stage of endothermic weight loss of 15 to $20 \%$ is similar for both the gels and the process taking place is dehydration of physically adsorbed water in the micropores of the gel (Clark and Lannutti 1984). However, the second stage of the weight loss and accompanying heat effect is remarkably different for the two gels. At this stage, gel-1 exhibited a sharp volatile loss of 25 to $30 \mathrm{wt} \%$ characterized by a small exotherm while gel- 2 exhibited a broad and slow volatile loss of $18 \mathrm{wt} \%$ characterized by an endotherm typical of crystalline boehmite transforming to $\gamma-\mathrm{Al}_{2} \mathrm{O}_{3}$ (Calvet et al 1964; Yoldas 1975b). Thus in order to obtain defect-free monoliths a control of the thermal schedule becomes more critical for gel-1 than for gel-2. It was found that a heating rate of $1 \mathrm{~K} \mathrm{~min}^{-1}$ up to $773 \mathrm{~K}$ was enough to result in defect-free monoliths of a few millimetres thickness. The density, specific surface area, average pore size and porosity of the specimens obtained by differently heat treating the gels are given in table 2 . One salient observation is that the pores remain uniform and monosize till $1273 \mathrm{~K}$. Even though density and average pore size increase while specific surface area decreases with increasing temperature, the effect is marginal till 1273 to $1373 \mathrm{~K}$. Above this temperature the effect is drastic due to the onset of $\theta$-to- $\alpha$ transformation of alumina. Gel-1 was found to be amorphous while gel-2 was crystalline boehmite as revealed by XRD (figure 3 ). The alumina obtained by sintering gel-1 was found to undergo the $\theta$-to- $\alpha$ transformation at a faster rate at $1373 \mathrm{~K}$ compared to that obtained from gel-2 (figure 4). This phase transformation enhances diffusion of the $\mathrm{Al}^{3+}$ ions resulting in densification (Yoldas 1975c). Even though the amorphous or boehmite gel transforming to $\gamma-\mathrm{Al}_{2} \mathrm{O}_{3}$ and $\alpha-\mathrm{Al}_{2} \mathrm{O}_{3}$ could be detected by XRD the series of $\gamma$-, 
Table 2. Specific surface area, mean pore diameter and bulk density of sintered gels.

\begin{tabular}{|c|c|c|c|c|c|c|}
\hline \multirow{2}{*}{$\begin{array}{l}\text { Sintering } \\
\text { temperature }(\mathbf{K})\end{array}$} & \multicolumn{3}{|c|}{ Gel-1 } & \multicolumn{3}{|c|}{ Gel-2 } \\
\hline & $\mathbf{S}$ & $\mathbf{R}$ & D & $\mathbf{S}$ & $\mathbf{R}$ & D \\
\hline 773 & 220 & 70 & $2 \cdot 4(65)$ & 230 & 60 & $2 \cdot 0(54)$ \\
\hline 1273 & 100 & 115 & $2 \cdot 6(71)$ & 105 & 90 & $2.8(76)$ \\
\hline 1373 & 50 & - & $3.5(88)$ & 80 & - & $3.0(80)$ \\
\hline 1473 & 10 & 524 & $3 \cdot 7(93)$ & 15 & 415 & $3.6(90)$ \\
\hline
\end{tabular}

S, Specific surface area $\left(\mathrm{m}^{2} \mathrm{~g}^{-1}\right) ; \mathrm{R}$, mean pore diameter $(\AA) ; \mathrm{D}$, bulk density $\left(\mathrm{g} \mathrm{cm}^{-3}\right)$; number in brackets represent $\% \mathrm{TD}$.

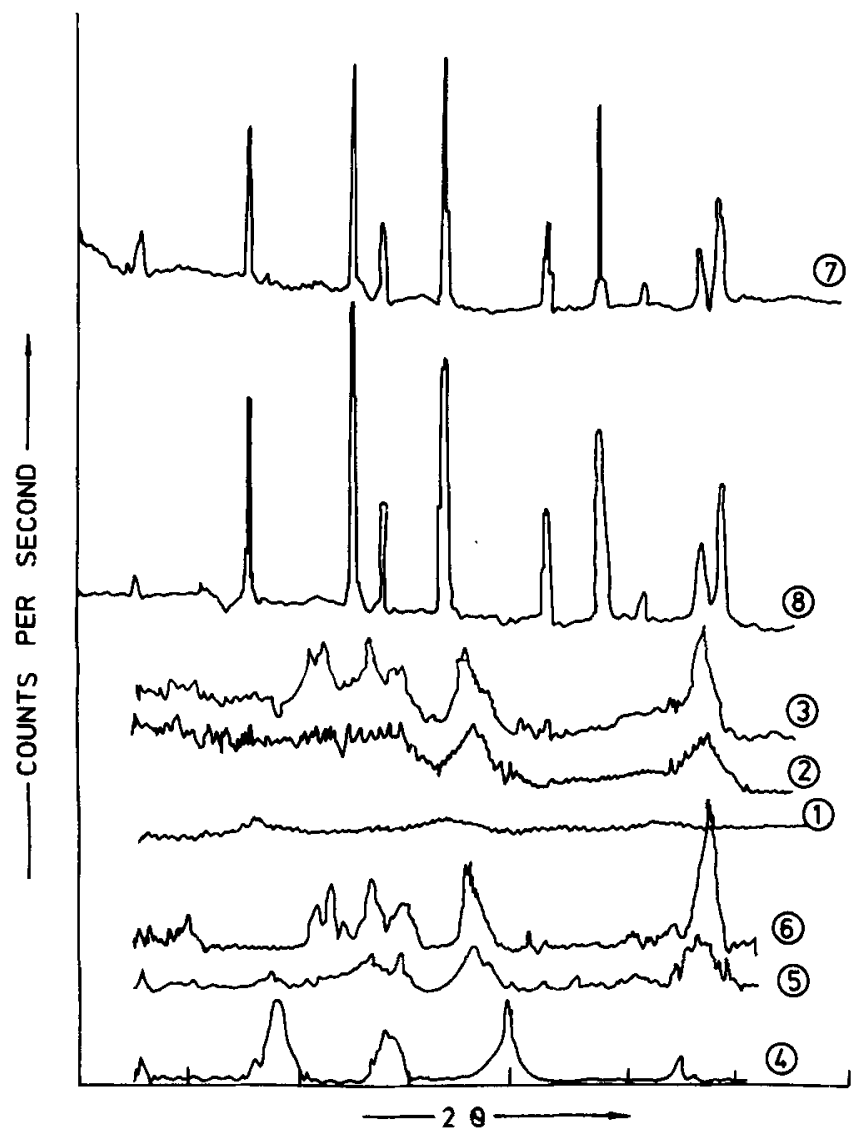

Figure 3. XRD patterns for $\mathrm{Al}_{2} \mathrm{O}_{3}$ gels differently heat-treated. 1, 2, 3, 7, Gel 1 heated at $300,773,1273$ and $1473 \mathrm{~K}$ for $2 \mathrm{~h} ; 4,5,6,8$, gel 2 heated at $300,773,1273$ and $1473 \mathrm{~K}$ for $2 \mathrm{~h}$. 


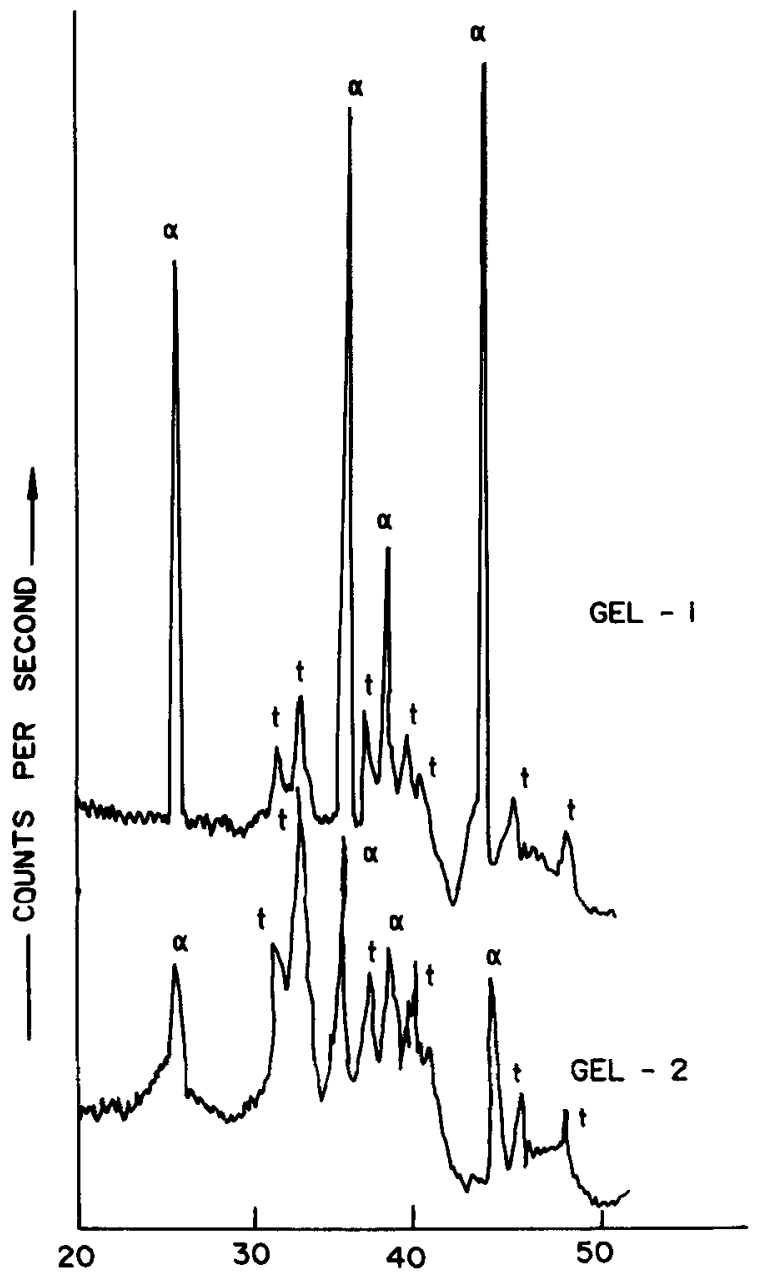

Figure 4. $\mathrm{XRD}$ pattern for $\mathrm{Al}_{2} \mathrm{O}_{3}$ gels heated at $1373 \mathrm{~K}$ for $2 \mathrm{~h}$.

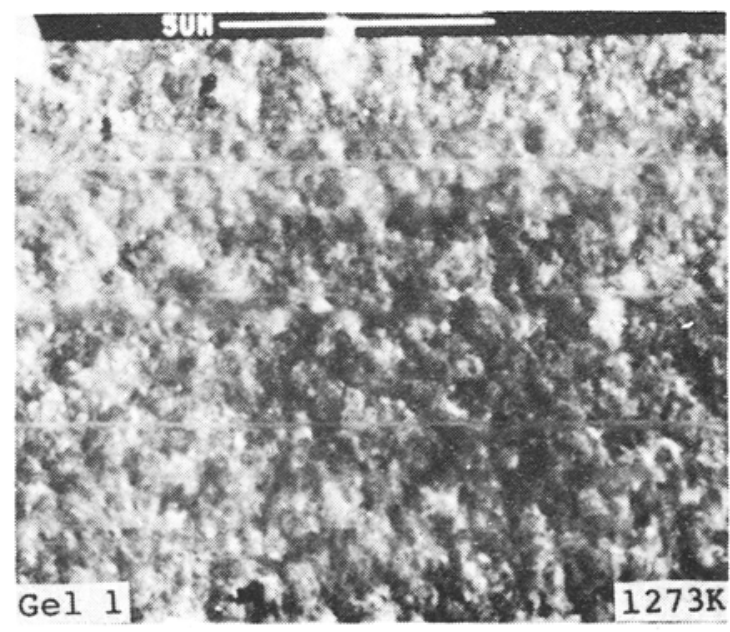

Figure 5. For caption, see p. 100. 

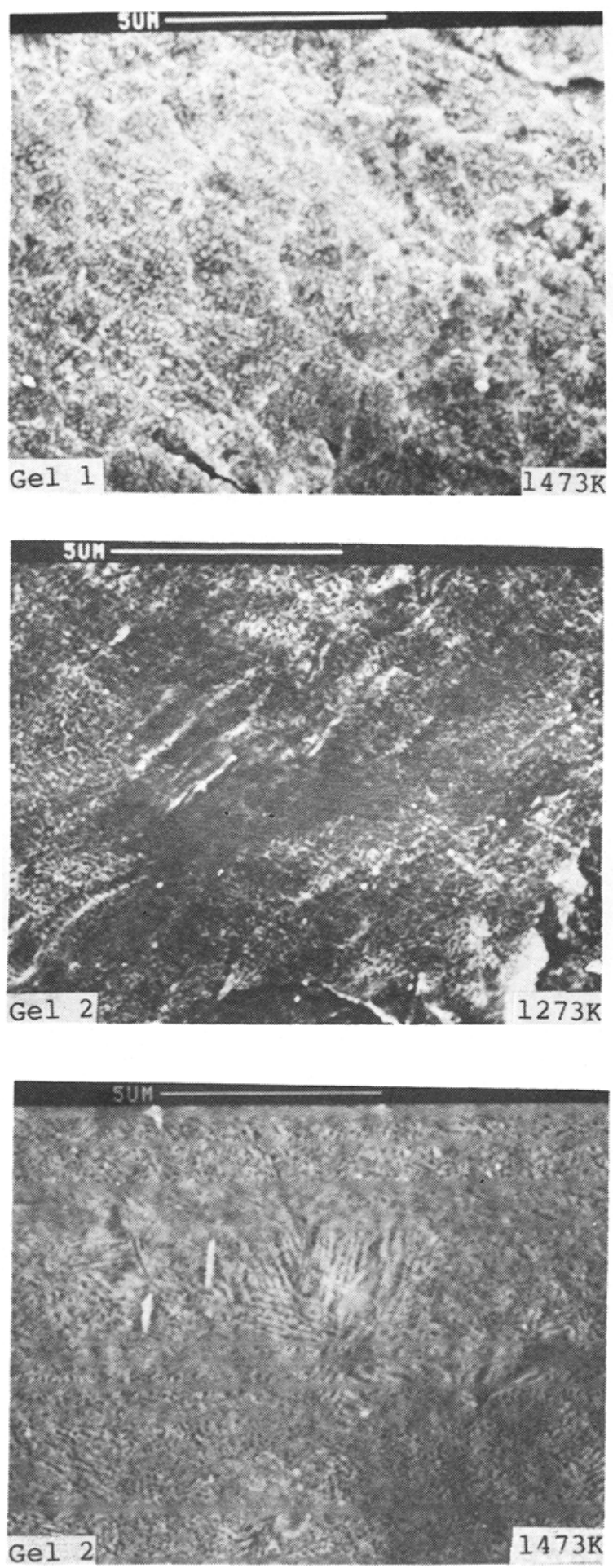

Figure 5. Scanning electron micrographs of alumina obtained from gels. 

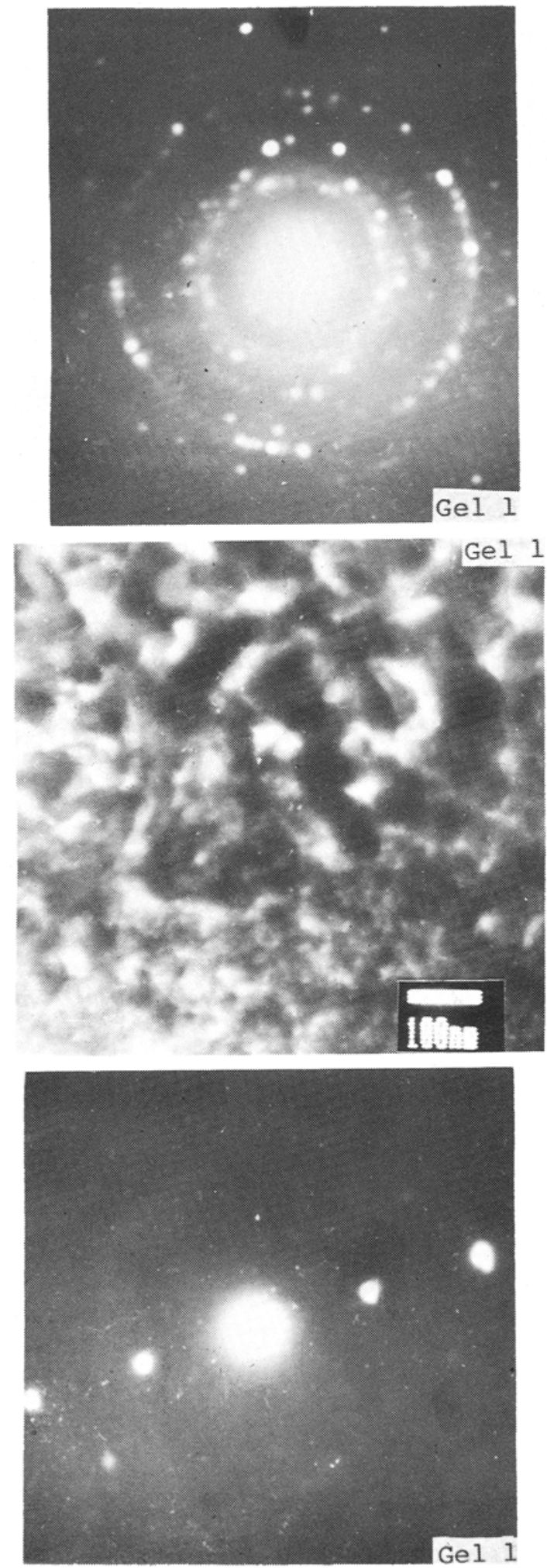

Figure 6. For caption, see p. 102. 

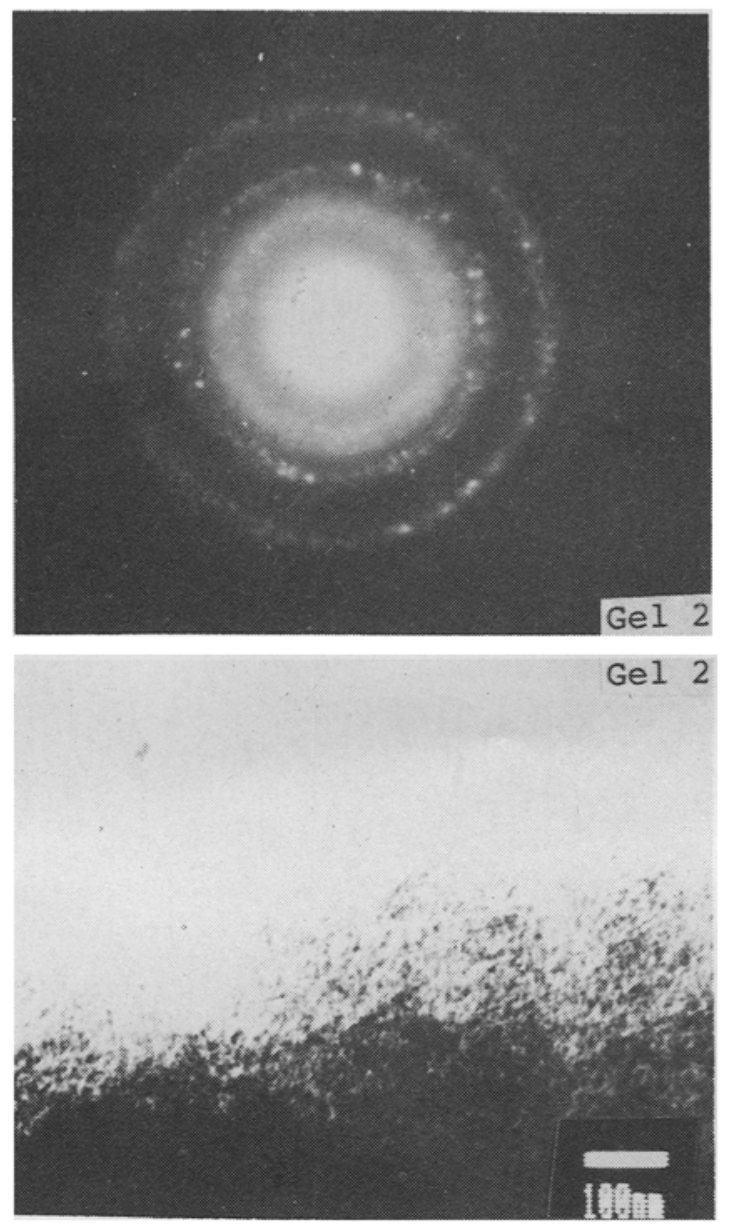

Figure 6. Transmission electron micrographs of alumina obtained from gels heated to $1373 \mathrm{~K}$.

$\eta$ - and $\theta$-phase evolution in the 773 to $1273 \mathrm{~K}$ range could not be detected by XRD (figure 3 ) due to their closely related and highly defective spinel structures.

The microstructural evolution upon heat treating the gels as revealed by SEM examination exhibited uniform submicron-size grains which could be attributed to the slow polymerization of the nanosize particles in the sol during gelation (figure 5). Gel-1-derived alumina exhibits particulate features due to granular morphology of the sol while gel-2-derived alumina exhibits strong oriented features due to the ordered packing of the charged boehmite platelets as gelation proceeds (Pierre and Uhlmann 1984; Kichang Song and In Jae Chung 1989). The transformed $\alpha$-phase also retained these features. For both these gels enhanced diffusion associated with the phase transformation from $\theta$ - to $\alpha-\mathrm{Al}_{2} \mathrm{O}_{3}$ as pointed out earlier and the fine grain structure providing short diffusion lengths led to better densification. Typical transmission electron micrographs and selected area diffraction patterns of the gels sintered at $1373 \mathrm{~K}$ ( $\theta$-to- $\alpha$ transformation stage) are shown in figure 6 . Gel-1-derived alumina 
shows the crystalline matrix having two-phase microstructure, the coarse and fine crystallite zones which were identified as $\alpha$ - and $\gamma-\mathrm{Al}_{2} \mathrm{O}_{3}$ respectively (Badkar and Bailey 1976; Dynes et al 1984). Under similar conditions gel-2-derived alumina exhibits fine $\gamma-\mathrm{Al}_{2} \mathrm{O}_{3}$ crystallites in which the transformation is yet to set in.

\section{Conclusion}

Fine-pore-size and high-specific-surface-area transparent $\gamma-\mathrm{Al}_{2} \mathrm{O}_{3}(54-65 \% \mathrm{TD}$ at $1273 \mathrm{~K}$ ) and high-density submicron-grain-sized non-transparent $\alpha-\mathrm{Al}_{2} \mathrm{O}_{3}$ monoliths (90-93\% TD at $1473 \mathrm{~K}$ ) could be obtained by appropriate choice of conditions of sol-gel processing. Better control over the process is possible with boehmite-based sol than amorphous sol. The sintering temperature could be drastically reduced due to the extremely fine-grained microstructure resulting in shorter path distances for material transport.

\section{Acknowledgement}

The authors are thankful to Dr S Banerjee, Head, Metallurgy Division, for his keen interest in this work. The authors are also grateful to Dr V N Vaidya, Fuel Chemistry Division; Mr A R Biswas, Atomic Fuels Division; Dr N C Soni and Dr G K Dey, Metallurgy Division, for their assistance in obtaining specific surface area, SEM, XRD and TEM results respectively.

\section{References}

Badker P A and Bailey J E 1976 J. Mater. Sci. 111794

Calvet E, Thibon H and Gambino M 1964 Bull. de La Soc. Chim. France 92132

Clark D E and Lannutti I J 1984 in Ultrastructure processing of ceramics, glasses and composites (eds) L L Hench and D R Ulrich (New York: Wiley) p. 126

Dynys F W, Jungberg M L and Hallorun J W 1984 in Better ceramics through chemistry (ed.) C J Brinker (North Holland: Elsevier Sci. Pub. Co. Inc.) p. 321

Matijevic E 1973 J. Colloid Interface Sci. 43217

Kichang Song and In Jae Chung 1989 J. Non-Cryst. Solids 10837

Pierre A C and Uhlman D R 1984 in Better ceramics thrqugh chemistry (ed.) C J Brinker (North Holland: Elsevier Sci. Pub. Co. Inc) p. 119

Yoldas B E 1975a Bull. Am. Ceram. Soc. 3287

Yoldas B E 1975b J. Mater. Sci. 101856

Yoldas B E 1975c Bull. Am. Ceram. Soc. 3289 